\title{
Burnout: Implicações das Fontes Organizacionais de Desajuste Indivíduo-Trabalho em Profissionais da Enfermagem
}

\author{
Burnout: Implications of the Organizational Sources of Job-Person \\ Mismatches in Nursing Workers
}

\author{
Mauricio Robayo Tamayo* \\ Universidade de Brasília
}

\begin{abstract}
Resumo
Esta pesquisa investigou a relação entre o burnout e as fontes organizacionais de desajuste indivíduotrabalho. Cento e noventa profissionais de enfermagem responderam uma escala de burnout e um questionário de fontes organizacionais de desajuste. Foram verificados níveis alto, moderado e baixo de burnout. Evidenciaram-se correlações diretas e significativas entre as fontes de desajuste e os três fatores de burnout. As fontes de desajuste Ausência de Coleguismo, Sobrecarga de Trabalho e Conflito Valores e Práticas Organizacionais revelaram-se preditores significativos para Exaustão Emocional. O fator Desumanização somente foi predito por Sobrecarga de Trabalho. O fator Decepção foi predito por Ausência de Coleguismo e Sobrecarga de Trabalho. A relação entre o burnout e as fontes organizacionais de desajuste foi evidenciada.

Palavras-chave: Burnout; Fontes organizacionais de desajuste indivíduo-trabalho; Profissionais de enfermagem.
\end{abstract}

\begin{abstract}
This research investigated the relation between burnout and the organizational sources of job-person mismatches. One hundred ninety nursing professionals answered a scale of burnout and one questionnaire of organizational sources of mismatches. High, medium and low levels of burnout were verified. Direct and significant correlations were verified between sources of mismatch and the three factors of burnout. The mismatches sources Absence of Team Spirit, Work Overload and Conflict of Values and Organizational Practices were significant predictors of Emotional Exhaustion. The Dehumanization factor was only predicted by the Work Overload factor. The Deception factor was predicted by the factors Absence of Team Spirit and Work Overload. The relationship between burnout and organizational sources of mismatches was evidenced.

Keywords: Burnout; Organizational sources of job-person mismatches; Nursing professionals.
\end{abstract}

O burnout (esgotamento profissional) é definido como uma síndrome psicológica decorrente da tensão emocional crônica no trabalho, constituída pelas dimensões: Exaustão Emocional, Desumanização ou Cinismo, e Decepção, denominada também Diminuição da Realização Pessoal ou Ineficácia (Maslach, Schaufeli, \& Leiter, 2001; Tamayo, 2008; Tamayo \& Tróccoli, 2002a, 2002b).

De acordo com esses autores, a dimensão Exaustão Emocional refere-se a um sentimento de fadiga e esgotamento energético, que esvazia os recursos emocionais do indivíduo. Esse componente do burnout retrata o aspecto de estresse individual da síndrome. A Desumanização,

\footnotetext{
*Endereço para correspondência: Faculdade de Ceilândia, Universidade de Brasília (UnB), Brasília, DF, Brasil. E-mail:maurobayo@yahoo.com.br

O autor agradece ao Conselho Nacional de Desenvolvimento Científico e Tecnológico (CNPq) pelo auxílio de pesquisa que permitiu a realização deste trabalho. $\mathrm{O}$ autor também agradece aos profissionais de enfermagem que participaram no estudo.
}

componente interpessoal do burnout, engloba as atitudes negativas de dureza, indiferença e distanciamento excessivo manifestas pelos profissionais no relacionamento com os usuários dos seus serviços (ex. pacientes, alunos). A dimensão Decepção relaciona-se a um sentimento de incompetência e a percepção de um desempenho insatisfatório no trabalho, retratando o aspecto de auto-avaliação do burnout_(Maslach et al., 2001; Tamayo, 2008; Tamayo \& Tróccoli, 2002a, 2002b).

Diversos autores alertam para a expansão do burnout e sinalizam que esse fenômeno, ao se nutrir de mudanças negativas no mundo do trabalho, está se alastrando de maneira preocupante. Por exemplo, Maslach e Leiter (1997), ao abordarem as proporções epidêmicas tomadas pelo burnout, descrevem o ambiente de trabalho atual como frio, hostil e muito exigente, sob os pontos de vista econômico e psicológico, aspectos que estão levando as pessoas à exaustão emocional e física.

Abordagens recentes do burnout (Maslach \& Leiter, 1997) explicam essa síndrome a partir de novas interpre- 
tações da noção de desajuste indivíduo-trabalho. Esses autores sustentam que a distância ou o desajuste entre a pessoa e o seu trabalho incrementam a probabilidade de desenvolvimento do burnout.

O processo de desajuste pode se apresentar em uma ou mais das seguintes áreas: carga de trabalho, recompensas, justiça, relacionamento com colegas, controle no trabalho e valores. O desajuste nessas áreas pode ocorrer quando a natureza do trabalho não está em harmonia com a natureza das pessoas, resultando em um incremento da exaustão, do cinismo e da ineficácia (Maslach, 2000; Maslach \& Leiter, 1997; Maslach et al., 2001; Tamayo, 2008).

Em função do desajuste, essas áreas ou fontes são definidas da seguinte forma por Maslach (2000): (a) sobrecarga: apresenta-se quando as demandas no trabalho excedem os limites humanos. As pessoas têm muitas coisas para fazer e pouco tempo para realizá-las, podendo atingir um estado em que não é possível recuperar a energia; (b) falta de controle: acontece quando as pessoas têm pouco controle sobre o trabalho que executam; (c) recompensas insuficientes: refere-se à falta de incentivos tanto externos, como por exemplo, o salário, quanto internos (reconhecimento e valorização do trabalho); (d) ausência de coleguismo: ocorre quando as pessoas perdem o sentido de relacionamentos positivos com os outros no trabalho; (e) falta de justiça: apresenta-se quando existe ineqüidade e ausência de procedimentos justos no local de trabalho e (f) conflito de valores: envolve a discrepância entre os valores declarados e as práticas organizacionais. Também abrange o desencontro entre os requisitos do trabalho e os princípios pessoais (cf. Maslach \& Leiter, 1997, para uma revisão detalhada das fontes de desajuste).

Cada uma dessas fontes de desajuste manifesta-se mediante características que podem tornar ameaçante o ambiente ocupacional do trabalhador, especialmente quando permanecem durante muito tempo. Por exemplo, na enfermagem, categoria profissional alvo da presente pesquisa, algumas dessas características são: o número reduzido de profissionais que trabalham no atendimento em saúde; as dificuldades em delimitar os diferentes papéis entre enfermeiros, técnicos e auxiliares de enfermagem; os conflitos interpessoais no trabalho; a falta de reconhecimento e valorização da profissão; o excesso de trabalho; o achatamento dos salários; a necessidade de vários vínculos empregatícios, que pode resultar em uma carga mensal extremamente longa e desgastante; os tratamentos longos e desconfortáveis dispensados aos pacientes, a falta de preparo para enfrentar demandas emocionais dos pacientes e suas famílias; o confronto diário com a dor, o sofrimento e a morte dos pacientes e a falta de suporte social no trabalho, o uso de tecnologia, etc. (Benevides-Pereira, 2002; Campos, Inocente, Alves, Guimarães, \& Areias, 2004; Murofuse, Abranches, \& Napoleão, 2005; Pronost \& Tap, 1996; Wilkinson, 1994). Em decorrência dessas característi- cas, a enfermagem é considerada uma categoria ocupacional especialmente vulnerável ao burnout (Aiken \& Sloane, 1997; Benevides-Pereira, 2002; Gil-Monte, Carretero, \& Roldan, 2005; Lautert, 1997; Patrick \& Lavery, 2007; Wilkinson, 1994).

Em um levantamento realizado entre 1978 e 1996, Schaufeli e Enzmann (1998) identificaram os profissionais de saúde como o maior grupo pesquisado em relação ao burnout (33,8\% dos estudos). Desse percentual, $17 \%$ das amostras eram de profissionais de enfermagem.

No Brasil, alguns estudos abordaram a relação do burnout na enfermagem com variáveis do trabalho e da organização. Por exemplo, Benevides-Pereira (2002) desenvolveu uma pesquisa junto a 228 profissionais de enfermagem (enfermeiros e auxiliares de enfermagem), lotados em três hospitais da região norte do Paraná. Esse trabalho evidenciou pontuações mais altas em exaustão emocional para o grupo que apresentava uma jornada semanal de 44 horas dedicadas à enfermagem. Também verificou uma correlação positiva entre jornada de trabalho e despersonalização.

Outra pesquisa, realizada por Lautert (1997), com uma amostra de profissionais de enfermagem de dois hospitais universitários de Porto Alegre $(N=341)$, abordou a relação do burnout com as características do trabalho dos diferentes setores de lotação. O estudo verificou média mais elevada em exaustão emocional entre os profissionais do setor de emergência, seguida pela média dos profissionais das unidades de internação clínica e cirúrgica de adultos e pela média dos trabalhadores lotados em unidades de tratamento intensivo. As médias mais altas em despersonalização também corresponderam aos profissionais do setor de emergência, seguida pela média do grupo lotado em unidades de tratamento intensivo.

Lautert (1997) explica esses resultados, no caso do setor de emergência, a partir de: a falta de informação das enfermeiras sobre os pacientes que estão atendendo, a falta de controle da situação associada a essa desinformação e a oscilação entre períodos intensos de trabalho, que exigem rapidez e destreza, e momentos de espera pelo inusitado e imprevisível.

Como características das unidades de tratamento intensivo relacionadas ao burnout, a autora destaca: o quadro clínico de risco dos pacientes que pode evoluir para a morte, a pressão sobre o tempo para a execução das tarefas, o uso de tecnologias sofisticadas e a sobrecarga de trabalho.

Em relação às unidades de internação clínica e cirúrgica, a pesquisadora salienta: os procedimentos repetitivos, as atividades burocráticas, a sobrecarga de trabalho e a natureza monótona de algumas tarefas.

O presente estudo também aborda o vínculo do burnout com aspectos organizacionais e do trabalho na enfermagem. Concretamente, com o intuito de verificar a relação do burnout e as fontes organizacionais de desajuste indivíduo-trabalho em profissionais de enfermagem, está pesquisa traçou os seguintes objetivos específicos: (a) 
estabelecer o nível nos fatores de burnout na amostra de participantes; (b) determinar o perfil de burnout apresentado pela categoria profissional participante no estudo e comparar esse perfil com os resultados obtidos em outras pesquisas; (c) determinar a percepção das fontes organizacionais de desajuste indivíduo-trabalho na amostra de participantes; (d) verificar as correlações entre as fontes organizacionais de desajuste e os fatores de burnout e estabelecer o poder de predição dessas fontes para estes fatores.

\section{Método}

\section{Amostra}

A amostra foi constituída por 190 trabalhadores de enfermagem responsáveis por labores assistenciais, de ambos os sexos ( 38 homens, 151 mulheres, 1 respondente não informou o sexo) de um hospital público do Distrito Federal (32 enfermeiros, 82 técnicos de enfermagem e 75 auxiliares de enfermagem, 1 respondente não informou o cargo). As características preponderantes da amostra foram: sexo feminino $(79,5 \%)$, técnicos de enfermagem $(43,2 \%)$, estado civil casado $(50,5 \%)$ e escolaridade de segundo grau completo $(49,5 \%)$. A idade média dos participantes foi de 34,50 anos $(D P=7,80)$ e a média do tempo de serviço foi de 6,8 anos $(D P=6,08)$.

A lotação dos respondentes correspondia aos seguintes setores: clínica médica, clínica cirúrgica, centro cirúrgico, cirurgia ambulatória, pediatria clínica, pediatria cirúrgica, berçário, maternidade, centro de terapia intensiva, pronto socorro, imagenologia, hemodiálise e centro de diagnóstico. O setor de ambulatório foi excluído das análises porque o número de questionários respondidos (2) não representou pelo menos $30 \%$ dos trabalhadores de enfermagem lotados nessa clínica.

\section{Instrumentos}

O burnout foi avaliado mediante a Escala de Caracterização do Burnout - ECB (Tamayo \& Tróccoli, 2005). Esse instrumento foi validado estatisticamente mediante análise dos componentes principais - principal components e análise do eixo fatorial principal - principal axis factoring, com rotação oblimin. Para a análise de confiabilidade foi adotado o alfa de Cronbach.

A escala é constituída de 46 itens, distribuídos em três fatores: Exaustão Emocional (alfa de Cronbach = 0,93; e.g. item: "Meu trabalho me exige mais do que posso dar".), Desumanização (alfa $=0,85$; e.g. item: "Trato alguns pacientes com frieza".) e Decepção (alfa $=0,91$; e.g. item: "Eu me sinto desiludido com meu trabalho".). Apresenta uma escala de resposta de 5 pontos (nunca a sempre).

Para avaliar as fontes de desajuste indivíduo-trabalho, foi utilizado o Questionário de Fontes de Desajuste (QFD), desenvolvido por Gianasi (2004). Considerando que esse instrumento foi validado junto a uma amostra de motoristas e cobradores de ônibus, foram realizadas mu- danças em alguns itens para adequá-lo ao ambiente hospitalar.

Após as adaptações desses itens, o instrumento foi submetido à análise semântica com um pequeno grupo de enfermeiras e auxiliares de enfermagem. Depois de incorporar as alterações sugeridas nessa atividade, $o$ questionário foi aplicado a uma amostra de 201 trabalhadores de enfermagem (enfermeiros, técnicos e auxiliares de enfermagem). Posteriormente, o instrumento foi submetido à validação estatística (análise dos componentes principais, análise do eixo factorial principal (com rotação oblimin) e análise de confiabilidade - alfa de Cronbach).

Como resultado dessas análises foram identificados os seguintes fatores: Ausência de Coleguismo (alfa de Cronbach $=0,84$; e.g. item: "Os colegas me ajudam nas tarefas quando preciso".), Sobrecarga de Trabalho (alfa $=0,82$; e.g. item: "Mesmo trabalhando mais, não consigo terminar minhas tarefas".) e Conflito Valores e Práticas Organizacionais (alfa $=0,85$; e.g. item: "O hospital exige dedicação, mas toma atitudes que prejudicam a qualidade do meu trabalho".). Apresenta uma escala de resposta de 5 pontos (nunca a sempre).

\section{Procedimentos de Coleta e Análise de Dados}

Uma vez obtidas a autorização institucional para a realização da pesquisa e a aprovação do Comitê de Ética em Pesquisa com Seres Humanos, foi iniciada a coleta de dados mediante aplicação individual e coletiva dos instrumentos no local de trabalho.

Os dados foram registrados e analisados no Programa de Estatística para Ciências Sociais (SPSS - Statistical Program of Social Sciences, versão 12). Inicialmente, foram realizadas análises descritivas e de caráter exploratório, conforme recomendam Tabachinick e Fidell (1996).

$\mathrm{Na}$ análise exploratória, realizada com 201 trabalhadores (amostra inicial), foram detectados 9 casos extremos univariados. Não foram identificados padrões sistemáticos nesses casos. Não foram identificados casos extremos multivariados mediante a adoção do critério $p<0,01$ para a distância Mahalanobis. Os dados faltosos, que não ultrapassaram o 5\%, foram substituídos pela média. Não foi identificado nenhum padrão de sistematicidade. Os valores de assimetria e achatamento das variáveis não reportaram a necessidade de efetuar nenhuma transformação.

A análise estatística dos dados envolveu técnicas descritivas (medidas de tendência central e de dispersão, análise de freqüência) e inferenciais (análise fatorial, análise de confiabilidade, correlação bi-variada e análise de regressão múltipla padrão).

\section{Resultados}

Em relação ao primeiro objetivo, estabelecer o nível nos fatores de burnout na amostra de participantes, foi verificado um escore baixo-moderado para o fator 
Exaustão Emocional e escores baixos para os fatores Desumanização e Decepção. O desvio-padrão desses fatores mostrou maior dispersão dos escores para exaustão emocional e dispersão mais discreta para desumanização e decepção (veja Tabela 1).

Tabela 1

Média e Desvio-Padrão dos Fatores de Burnout e das Fontes Organizacionais de Desajuste $(N=190)$

\begin{tabular}{lll}
\hline Fatores & $M$ & $D P$ \\
\hline $\begin{array}{l}\text { Escala de burnout } \\
\quad \text { Exaustão emocional }\end{array}$ & 2,46 & 0,74 \\
$\quad \begin{array}{l}\text { Desumanização } \\
\quad \text { Decepção }\end{array}$ & 1,70 & 0,41 \\
$\quad$ & 1,84 & 0,58 \\
Questionário fontes de desajuste & & \\
$\quad$ Ausência de coleguismo & 2,51 & 0,69 \\
$\quad$ Sobrecarga de trabalho & 2,83 & 0,74 \\
$\quad$ Conflito valores e práticas & 3,15 & 0,82 \\
\hline
\end{tabular}

Os níveis de burnout baixo, médio e alto foram calculados a partir dos percentis da distribuição, tomando como referência o padrão de resposta da própria amostra, tal como sugerido por Maslach e Jackson (1986). Esses resultados agruparam os participantes localizados em níveis similares, concomitantemente nos três fatores do burnout (ex. exaustão emocional alta, desumanização alta e decepção alta). Foram verificados os seguintes resultados: 12,6\% (24 respondentes) localizaram-se no nível baixo; 8,4\% (16 participantes) situaram-se no nível médio e 17,4\% (33 trabalhadores) agruparam-se no nível alto.

Em relação ao segundo objetivo, determinar o perfil de burnout na amostra de participantes, a Exaustão Emocional foi o fator que obteve a média mais alta, seguido pela média do fator Decepção e finalmente pela média do fator Desumanização.

No terceiro objetivo, determinar a percepção das fontes organizacionais de desajuste indivíduo-trabalho da amostra de participantes, foi verificado um escore baixo-moderado para os fatores Ausência de Coleguismo e Sobrecarga de Trabalho e um escore moderado para o fator Conflito de Valores e Práticas Organizacionais. Os desvios padrão desses fatores foram muito próximos (veja Tabela 1).

Nos resultados referentes ao quarto objetivo, verificar as correlações entre as fontes organizacionais de desajuste e os fatores de burnout e estabelecer o poder de predição dessas fontes para estes fatores, foram evidenciados os seguintes resultados.

Em relação à primeira parte desse objetivo, todas as fontes de desajuste apresentaram correlações diretas e significativas com os fatores da síndrome. Especificamente, o fator Exaustão Emocional apresentou correlações altas com os fatores Sobrecarga de Trabalho $(r=$
$0,70 ; p=0,01)$ e Ausência de Coleguismo $(r=0,47 ; p=$ $0,01)$ e uma correlação moderada com o fator Conflito de Valores e Práticas Organizacionais $(r=0,34 ; p=0,01)$.

$\mathrm{O}$ fator Desumanização também apresentou correlações diretas e moderadas com as três fontes de desajuste: Sobrecarga de Trabalho $(r=0,41 ; p=0,01)$; Ausência de Coleguismo ( $r=0,27 ; p=0,01)$ e Conflito Valores e Práticas Organizacionais $(r=0,19 ; p=0,01)$.

O último fator do burnout, Decepção, evidenciou uma correlação alta e direta com o fator Sobrecarga de Trabalho $(r=0,65 ; p=0,01)$ e correlações moderadas e positivas com as dimensões Ausência de Coleguismo ( $r=$ $0,46 ; p=0,01)$ e Conflito Valores e Práticas Organizacionais $(r=0,28 ; p=0,01)$.

Acerca da segunda parte do objetivo, estabelecer o poder de predição das fontes organizacionais de desajuste para os fatores de burnout, foram evidenciados os seguintes resultados.

$\mathrm{Na}$ regressão múltipla padrão calculada para o fator Exaustão Emocional (veja Tabela 2), observa-se que o $R$ para a regressão foi significativamente diferente de zero $F(3,186)=76,11, p=0,000$. As três fontes organizacionais de desajuste contribuíram significativamente para a predição da Exaustão Emocional: Ausência de Coleguismo $\left(s r^{2}=0,03 ; \beta=0,19\right)$, Sobrecarga de Trabalho $\left(s r^{2}=0,30 ; \beta=0,60\right)$ e Conflito de Valores e Práticas Organizacionais $\left(s r^{2}=0,01 ; \beta=0,11\right)$. No total, $55 \%$ (54\% ajustado) da variabilidade em Exaustão Emocional foi predita pelos escores dessas três variáveis.

A segunda regressão realizada para o fator de burnout Desumanização, apresentada na Tabela 3, mostra que o $R$ para a regressão foi significativamente diferente de zero $F(3,186)=13,972, p=0,000$. Somente a variável independente Sobrecarga de Trabalho contribuiu significativamente para a predição de Desumanização $\left(s r^{2}=\right.$ $0,10 ; \beta=0,35)$. No total, $18 \%$ ( $17 \%$ ajustado) da variabilidade em Desumanização foi predita pelos escores das fontes de desajuste.

A última regressão, desenvolvida para o fator de burnout Decepção (Tabela 4), evidenciou um $R$ para a regressão significativamente diferente de zero $F(3,186)$ $=57,590, p=0,000$. Unicamente duas das variáveis independentes, Ausência de Coleguismo $\left(s r^{2}=0,04 ; \beta=\right.$ $0,22)$ e Sobrecarga de Trabalho $\left(s r^{2}=0,25 ; \beta=0,55\right)$, contribuíram significativamente para a predição do fator Decepção. No total, 48\% (47\% ajustado) da variabilidade em Decepção foi predito pelos escores das fontes de desajuste.

\section{Discussão}

A finalidade da presente pesquisa foi investigar a relação entre o burnout e as fontes organizacionais de desajuste indivíduo-trabalho em uma amostra de profissionais de enfermagem de um hospital público. Primeiramente, foram calculados os escores nos fatores de burnout, determinados os níveis dessa síndrome e levan- 
Psicologia: Reflexão e Crítica, 22(3), 474-482.

Tabela 2

Regressão Linear Múltipla Padrão das Fontes Organizacionais de Desajuste para o Fator Exaustão Emocional

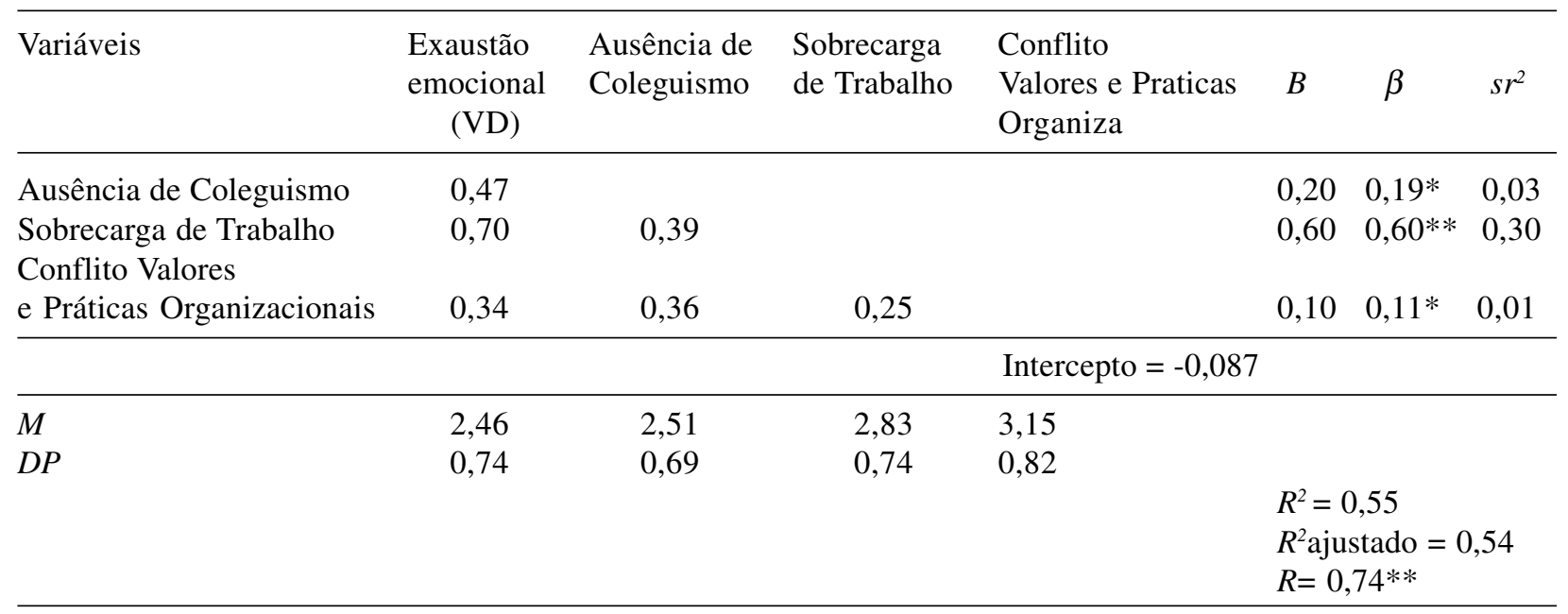

Nota. $* p<0,05 ; * * p<0,001$.

Tabela 3

Regressão Linear Múltipla Padrão das Fontes Organizacionais de Desajuste para o Fator Desumanização

\begin{tabular}{|c|c|c|c|c|c|c|c|}
\hline Variáveis & $\begin{array}{l}\text { Desuma- } \\
\text { nização } \\
\text { (VD) }\end{array}$ & $\begin{array}{l}\text { Ausência de } \\
\text { Coleguismo }\end{array}$ & $\begin{array}{l}\text { Sobrecarga } \\
\text { de Trabalho }\end{array}$ & $\begin{array}{l}\text { Conflito } \\
\text { Valores e Praticas } \\
\text { Organiza }\end{array}$ & $B$ & $\beta$ & $s r^{2}$ \\
\hline Ausência de Coleguismo & 0,27 & & & & 0,07 & 0,12 & \\
\hline Sobrecarga de Trabalho & 0,41 & 0,39 & & & 0,19 & $0,35^{* *}$ & 0,10 \\
\hline Conflito de Valores e & & & & & & & \\
\hline Práticas Organizacionais & 0,19 & 0,35 & 0,25 & & 0,03 & 0,06 & \\
\hline \multicolumn{8}{|c|}{ Intercepto $=0,900$} \\
\hline$M$ & 1,70 & 2,51 & 2,83 & 3,15 & & & \\
\hline \multirow[t]{4}{*}{$D P$} & 0,41 & 0,69 & 0,74 & 0,82 & & & \\
\hline & & & & & \multirow{3}{*}{\multicolumn{3}{|c|}{$\begin{array}{l}R^{2}=0,18 \\
R^{2} \text { ajustado }=0,17 \\
R=0,43^{* *}\end{array}$}} \\
\hline & & & & & & & \\
\hline & & & & & & & \\
\hline
\end{tabular}

Nota. $* * p<0,001$.

Tabela 4

Regressão Linear Múltipla Padrão das Fontes Organizacionais de Desajuste para o Fator Decepção

\begin{tabular}{|c|c|c|c|c|c|c|c|}
\hline Variáveis & $\begin{array}{l}\text { Decepção } \\
\text { (VD) }\end{array}$ & $\begin{array}{l}\text { Ausência de } \\
\text { Coleguismo }\end{array}$ & $\begin{array}{l}\text { Sobrecarga } \\
\text { de Trabalho }\end{array}$ & $\begin{array}{l}\text { Conflito } \\
\text { Valores e Praticas } \\
\text { Organiza }\end{array}$ & $B$ & $\beta$ & $s r^{2}$ \\
\hline Ausência de Coleguismo & 0,46 & & & & 0,19 & $0,22 * *$ & 0,04 \\
\hline Sobrecarga de Trabalho & 0,65 & 0,39 & & & 0,43 & $0,55 * *$ & 0,25 \\
\hline Conflito de Valores e & & & & & & & \\
\hline Práticas Organizacionais & 0,28 & 0,36 & 0,25 & & 0,04 & 0,06 & \\
\hline \multicolumn{8}{|c|}{ Intercepto $=0,007$} \\
\hline$M$ & 1,84 & 2,51 & 2,83 & 3,15 & \multirow{4}{*}{\multicolumn{3}{|c|}{$\begin{array}{l}R^{2}=0,48 \\
R^{2} \text { ajustado }=0,47 \\
R=0,69 * *\end{array}$}} \\
\hline$D P$ & 0,58 & 0,69 & 0,74 & 0,82 & & & \\
\hline & & & & & & & \\
\hline & & & & & & & \\
\hline
\end{tabular}

Nota. $* * p \leq 0,01$. 
tado o seu perfil na amostra de participantes. Posteriormente, foi estabelecida a percepção dos respondentes em relação às fontes de desajuste. Por fim, foram verificadas as correlações entre os fatores de burnout e as fontes de desajuste e foi determinado o poder de predição dessas fontes em relação a cada um dos fatores da síndrome. Os resultados encontrados são discutidos a seguir.

As médias nas dimensões de burnout apontaram freqüência baixa-moderada para Exaustão Emocional e freqüências baixas para os outros dois fatores dessa síndrome. Em relação ao perfil de burnout da amostra, cabe salientar que o escore médio mais alto correspondeu à Exaustão Emocional e o escore médio mais baixo ficou por conta do fator Desumanização. O segundo escore foi ocupado pelo fator Decepção. Esse perfil de burnout coincidiu com os resultados encontrados em outros estudos nacionais realizados com profissionais de saúde (e.g. Borges, Argolo, \& Baker, 2006, desenvolvido em uma maternidade pública e Tamayo, Argolo, \& Borges, 2005, realizado em Unidades Básicas de Saúde e hospitais).

É importante salientar que a exaustão emocional, considerada uma variável típica de estresse individual, é conceituada como o aspecto central do burnout (Cordes \& Dougherty, 1993; Maslach et al., 2001). É provável que os escores mais altos evidenciados nessa variável decorram da maior facilidade em admitir sentimentos de estresse e de desgaste do que em aceitar a adoção de atitudes de indiferença, distanciamento e frieza com os usuários ou a presença de sentimentos de inadequação e falta de realização pessoal e profissional no trabalho. Nesse sentido, a aceitação do estresse e do desgaste em trabalhadores da enfermagem pode ser compatível com a identidade social dessa profissão, que enfatiza o seu caráter missionário e a dedicação necessária para cuidar de pacientes que, em razão da sua condição clínica, padecem de dor e sofrimento, demandando atenção e assistência permanentes.

O escore mais elevado em Exaustão Emocional também pode decorrer do fato de a amostra ter sido constituída predominantemente por mulheres. Pesquisas mostram uma maior prevalência da exaustão emocional no sexo feminino e de despersonalização no masculino (Gil-Monte \& Peiró, 1997; Schaufeli \& Enzmann, 1998). A maior exaustão em mulheres está relacionada à dupla jornada (responsabilidades do trabalho e do lar) e aos estereótipos referentes ao gênero, em que as mulheres são mais responsivas emocionalmente, enquanto os homens apresentam atitudes mais instrumentais (Schaufeli \& Enzmann, 1998).

A explicação dessas diferenças pode estar ligada à imagem tradicional da enfermagem como uma profissão feminina, fortemente vinculada ao cuidado humano (Gil-Monte, 2002). A mulher é vista como responsável pelos cuidados de saúde no domínio privado (doméstico), condição que transpõe "naturalmente" para o domínio profissional, em razão dos seus atributos e qualidades (Lopes, 1996).
Acerca dos níveis de burnout, a pesquisa verificou uma porcentagem considerável de profissionais que apresentaram condições alta e moderada dessa síndrome, considerando o padrão de resposta da própria amostra. Por essa razão, ainda que esses níveis não retratem escores máximos na escala de resposta, com amplitude de 1 a 5 , eles indicam a existência de subgrupos de participantes com médias mais elevadas concomitantemente nos três fatores, em comparação com o conjunto total de respondentes. Esses dados sugerem a possibilidade de subgrupos de trabalhadores estarem vivenciando um processo de burnout. Nesse sentido, os resultados alertam para a necessidade de implementação de medidas organizacionais de prevenção e intervenção com a finalidade de frear uma possível evolução desse processo.

Em relação à percepção das fontes organizacionais de desajuste indivíduo-trabalho da amostra de participantes, esta se caracterizou por frequiência baixa-moderada nos fatores Sobrecarga de Trabalho e Ausência de Coleguismo e por frequiência moderada no fator Conflito Valores e Práticas Organizacionais.

Apesar de a enfermagem ser descrita como uma atividade desgastante em razão de características tais como excesso de atividades, escassez de pessoal, diversidade de turnos etc, a percepção da sobrecarga de trabalho, referente ao hospital onde foi realizada a pesquisa, tendeu a um nível moderado. Esse resultado pode ser explicado pelo fato de $77 \%$ da amostra ter carga horária semanal de 30 horas nessa instituição.

O escore observado no fator Ausência de Coleguismo, ainda que não foi elevado, evidenciou a percepção dos respondentes de falta de apoio e união entre os colegas, características cruciais em atividades laborais realizadas em equipe, como no caso enfermagem hospitalar. Apesar de comportamentos de coleguismo serem muito relevantes nessa ocupação, características típicas do trabalho nessa profissão, como as escalas, os turnos, o ritmo intenso, a sobrecarga, a falta de períodos de descanso e a necessidade de manter vários vínculos empregatícios, podem dificultar a consolidação de equipes coesas e estáveis, impedindo a construção de redes de suporte social.

A média do fator Conflito Valores e Práticas Organizacionais atingiu um nível moderado, revelando a inconsistência entre o tipo de atendimento que se espera que os profissionais dêem aos usuários e o tratamento que aqueles recebem por parte da organização. $\mathrm{Na}$ ótica do discurso oficial da humanização da assistência hospitalar verifica-se uma preocupação com a melhoria das condições de trabalho dos profissionais de saúde. Deslandes (2004), ao se referir a essas condições - remuneração inadequada, falta de incentivo e carga de trabalho considerável - sustenta que "Humanizar a assistência em saúde é humanizar a produção dessa assistência" (p. 10). Entretanto, essa autora considera que a deficiência do diálogo e a debilidade do processo comunicacional entre profissionais e usuários e entre profissionais e gestores, não só comprometem a qualidade do atendimento, mas 
também mantêm esses profissionais reféns de condições de trabalho inadequadas, favorecedoras de desgaste e sofrimento.

No que diz respeito à associação entre as fontes de desajuste e os fatores do burnout, a dimensão Sobrecarga de Trabalho correlacionou-se significativamente com todos os fatores de burnout, mostrando ser um preditor significativo para estes. A sobrecarga é uma fonte tradicional de estresse apontada na literatura (cf. Beehr \& Glazer, 2005; Cooper, Dewe, \& O’ Driscoll, 2001). Diversas pesquisas têm evidenciado o papel das demandas excessivas como preditor importante para a exaustão emocional (Bakker, Demerouti, \& Euwema, 2005; Janssen, Schaufeli \& Houkes, 1999; Lee \& Ashforth, 1996; Tamayo \& Silva, 2006; Tamayo \& Tróccoli, 2002a, 2002b). Resultados desses estudos sugerem que indivíduos afetados pelas demandas no trabalho podem desenvolver um processo de esgotamento emocional, em que as suas energias são sugadas, tornando impossível a recuperação (Maslach, 2005).

De acordo com essa autora, não é de surpreender que a sobrecarga de trabalho seja o melhor preditor da exaustão, considerando que as pessoas submetidas a essa condição também sofrem um desequilíbrio na sua vida doméstica. Esse aspecto fica muito evidente no campo da enfermagem, tradicionalmente ocupado por mulheres, em que a dupla jornada é muito comum. Na amostra deste estudo, por exemplo, 40,39\% das participantes têm uma carga horária semanal entre 41 e 70 horas (considerando todos os empregos) e $23,52 \%$ trabalha mais de 70 horas (incluindo todos os empregos). Essa sobrecarga pode comprometer não só a vida familiar, como também pode dificultar o investimento em projetos de desenvolvimento profissional e pessoal.

A fonte de desajuste Sobrecarga de Trabalho também foi preditor significativo para as dimensões Desumanização e Decepção, mostrando como essa variável tem forte influência sobre o bem-estar geral e a saúde do trabalhador. A sobrecarga na área de enfermagem não está relacionada somente à quantidade de atividades que o indivíduo deve realizar, mas também ao fato de lidar continuamente com experiências emocionalmente onerosas como a dor, o sofrimento e a morte dos pacientes.

O fator Ausência de Coleguismo correlacionou-se positivamente com as três dimensões do burnout, mas só foi preditor significativo para duas: Exaustão Emocional e Decepção, contribuindo de forma mais notória na explicação da variância desta última.

O fator Ausência de Coleguismo retrata a importância do suporte social e da coesão, colaboração e resolução de conflitos interpessoais no ambiente ocupacional. Como já foi mencionado, a realização das atividades na enfermagem hospitalar acontece comumente em equipes. Nesses conjuntos, a centralidade do trabalho coletivo manifesta-se na obtenção de resultados que expressem a sua finalidade: a atenção integral às necessidades de saúde do paciente. Essa centralidade pode ser aprimorada me- diante uma comunicação direcionada ao consenso entre os profissionais no cotidiano do trabalho, tornando-se, dessa forma, em um potencializador da sua realização (Shimizu \& Ciampone, 2004).

É provável que a hierarquia rígida estabelecida pelo grau de escolaridade e a ênfase no domínio técnico existentes no campo de enfermagem possam dificultar a coesão da equipe, afetando a execução coletiva das atividades e minando o sentimento de realização pessoal que os indivíduos podem derivar do seu trabalho. Pesquisas destacam que grande parte dos conflitos da equipe de enfermagem decorre da postura autoritária e centralizadora da enfermeira em relação aos demais membros da equipe (Shimizu \& Ciampone, 2004). Além disso, as relações interpessoais têm sido identificadas como estressores tanto em enfermeiros assistenciais, quanto em enfermeiros administrativos e docentes (Murofuse, Abranches, \& Napoleão, 2005).

Em relação à Exaustão Emocional, cabe mencionar que a falta de coleguismo pode tornar o trabalho mais estafante em situações em que a dinâmica da equipe não contempla as necessidades pessoais dos seus membros nem permite administrar o desgaste decorrente do trato com pacientes que apresentam dor e sofrimento. A convivência em equipe no trabalho pode representar um esforço extra para manter a união do grupo, em uma atividade estressante por natureza, tal como foi verificado por Shimizu e Ciampone (2004). O poder de predição em relação à exaustão emocional de variáveis que traduzem o apoio e a colaboração dos colegas de trabalho, como o suporte social ou a administração dos conflitos com o staff, já foi verificado em diversas pesquisas (Bakker et al., 2005; Lee \& Ashforth, 1996; Payne, 2001, entre outras), inclusive em estudos nacionais (Tamayo \& Tróccoli, 2002a).

A fonte de desajuste Conflito de Valores e Práticas Organizacionais correlacionou-se significativamente, de forma direta, com as três dimensões do burnout, sendo preditor significativo somente para exaustão emocional. O impacto dos valores sobre o burnout já foi verificado em algumas pesquisas, sugerindo que estes podem ter um papel-chave na predição dessa síndrome (Maslach, 2005). No Brasil, já foi evidenciada a relação entre os valores organizacionais e os fatores de burnout (vide Borges et al., 2006; Borges, Argolo, Pereira, Machado, \& Silva, 2002; Tamayo, 1997; Tamayo \& Tróccoli, 2002b).

Abordando a relação da Exaustão Emocional com os valores da organização, Tamayo e Tróccoli (2002b) consideram que o indivíduo sente-se menos exaurido quando percebe condições favoráveis à busca dos seus próprios interesses e à conciliação das suas metas com os objetivos da empresa, e quando avalia que a sua organização se preocupa com o bem-estar dos seus empregados. Essa percepção pode refletir a coerência entre aquilo que a organização declara e as práticas por ela adotadas.

A discrepância entre esses aspectos, particularmente no que concerne à forma como a organização trata a seus 
empregados, pode se ver refletida em determinações que enfraqueçam a saúde dos trabalhadores. As precárias condições laborais a que frequentemente se vêem submetidos os profissionais da saúde (falta de recursos, baixos salários, desvalorização da profissão, sobrecarga de trabalho, falta de reconhecimento etc.) podem colocá-los diante de uma situação paradoxal: a possibilidade de adoecer enquanto cuidam da saúde de outras pessoas. Essa contradição torna-se ainda mais forte considerando que as organizações onde trabalham esses profissionais fazem parte de um sistema público que concebe e defende a saúde como um direito social.

\section{Limitações}

Em relação às limitações do presente estudo, cabe salientar o seu restrito poder de generalização, uma vez que a pesquisa foi desenvolvida com uma amostra acidental. Também é importante sublinhar que somente foram verificadas três fontes organizacionais de desajuste indivíduo-trabalho na analise fatorial do instrumento utilizado para mensurar esse construto. Essa medida apresentou propriedades psicométricas satisfatórias (índices de consistência interna superiores a 0,80). Entretanto, é importante que a sua estrutura seja reavaliada para esclarecer por que motivo outras fontes de desajuste não aparecem representadas. A pesquisa também apresentou as limitações próprias de um estudo transversal, assim como as restrições inerentes ao uso de instrumentos de auto-relato.

\section{Recomendações Práticas}

Como mencionado anteriormente, os percentuais de trabalhadores acometidos por níveis altos e moderados de burnout sugerem que a organização deve tomar medidas preventivas e de intervenção para conter o desenvolvimento dessa síndrome. Essas medidas devem ser desenhadas tanto para melhorar os recursos de enfrentamento ao estresse dos indivíduos, quanto para corrigir as práticas administrativas da organização (cf. Bamber, 2006; Burke \& Richardsen, 2000; Gil-Monte, 2005; Gil-Monte \& Peiró, 1997; Masalch \& Leiter, 1997; Maslach et al., 2001; Schaufeli \& Enzmann, 1998).

Considerando o papel preponderante da sobrecarga de trabalho verificado nesta pesquisa, sugere-se adotar a recomendação de Bakker et al. (2005), no sentido de desenhar demandas no trabalho a que as pessoas possam atender sem comprometer a sua própria saúde. Caso isso não seja possível, a organização deve prover recursos que possam amenizar efetivamente os efeitos causados por essas demandas.

A organização deve acompanhar os conflitos que surjam nas equipes de trabalho e promover espaços de discussão para buscar soluções para essas desavenças. Também é desejável fomentar espaços para que os trabalhadores possam discutir os efeitos do estresse organizacional e possam levantar alternativas para evitar ou amenizar esses efeitos.
Os gestores da instituição devem atentar para a afinidade entre os valores declarados e as práticas organizacionais adotadas, dando especial atenção ao favorecimento de condições de trabalho adequadas, que fomentem a saúde e o bem-estar dos seus empregados.

Em relação à prevenção do burnout, os especialistas recomendam atuar inicialmente sobre os estressores que influenciam diretamente a exaustão emocional (ajustar a sobrecarga de trabalho para torná-la mais administrável, redistribuir tarefas para quebrar a monotonia e favorecer a resolução de conflitos interpessoais). Além disso, também sugerem o fomento do empoderamento dos trabalhadores da organização para que sejam participes da construção de um ambiente ocupacional saudável.

\section{Conclusão Geral}

A pesquisa constatou a relação entre os fatores de burnout e as fontes organizacionais de desajuste indivíduo-trabalho. A ocorrência de níveis de burnout foi evidenciada. Também foram verificadas correlações entre esses construtos e foi confirmada a capacidade de predição das fontes de desajuste para os fatores de burnout. Novos estudos devem abordar a relação entre o burnout e as fontes de desajuste em diferentes categorias ocupacionais e tipos de organizações para que a validade dessa proposta teórica possa ganhar maior suporte empírico. Também são desejáveis pesquisas qualitativas que ajudem a esclarecer quais fontes de desajuste são mais importantes para diferentes grupos ocupacionais.

\section{Referências}

Aiken, L. H., \& Sloane, D. M. (1997). Effects of organizational innovation in AIDS care on burnout among urban hospital nurses. Work and Occupations, 24, 453-477.

Bakker, A. B., Demerouti, E., \& Euwema, M. C. (2005). Job resources buffer the impact of job demands on burnout. Journal of Occupational Health Psychology, 10(2), 170-180.

Bamber, M. R. (2006). Cognitive behavioral therapy for other work-related anxiety syndromes. In M. R. Bamber (Eds.) CBT for occupational stress in health professionals: Introducing a schema-focused approach (pp. 82-91). New York: Routledge.

Beehr, T. A., \& Glazer, S. (2005). Organizational role stress. In J. Barling, E. K. Kelloway, \& M. R. Frone (Eds.), Handbook of work stress (pp. 7-34). Thousand Oaks, CA: Sage.

Benevides-Pereira, A. M. T. (2002). As atividades de enfermagem em hospital: Um fator de vulnerabilidade ao burnout. In A. M. T. Benevides-Pereira (Ed.), Burnout: Quando o trabalho ameaça a saúde do trabalhador (pp. 133-156). São Paulo, SP: Casa do Psicólogo.

Borges, L. O., Argolo, J. C. T., \& Baker, M. C. S. (2006). Os valores organizacionais e a síndrome de burnout: Dois momentos em uma maternidade pública. Psicologia: Reflexão e Crítica, 19(1), 34-43.

Borges, L. O., Argolo, J. C. T., Pereira, A. L. S., Machado, E. A P., \& Silva, W. S. (2002). A síndrome de burnout e os valores organizacionais: Um estudo comparativo em hospitais universitários. Psicologia: Reflexão e Crítica, 15(1), 189-200. 
Burke, R. J., \& Richardsen, A. M. (2000). Organizational-level interventions designed to reduce occupational stressors. In P. Dewe, M. Leiter, \& T. Cox (Eds.), Coping, health and organizations (pp. 191-210). Boca Raton, FL: CRS Press.

Campos, C. R., Inocente, N. J., Alves, O. D., Guimarães, L. A. M., \& Areias, M. E. Q. (2004). Síndrome de burnout em profissionais da saúde. In L. A. M. Guimarães \& S. Grubits (Eds.), Saúde mental e trabalho: Vol. 3 (pp. 63-78). São Paulo, SP: Casa do Psicólogo.

Cooper, C. L., Dewe, P. J., \& O’Driscoll, M. P. (2001). Organizational stress: A review and critique of theory, research, and applications. London: Sage.

Cordes, C. L., \& Dougherty, T. W. (1993). A review and an integration of research on job burnout. Academy of Management Review, 18(4), 621-656.

Deslandes, S. F. (2004). Análise do discurso oficial sobre a humanização da assistência hospitalar. Ciência \& Saúde Coletiva, 9(1), 7-14.

Gianasi, L. (2004). As fontes de desajuste físico e emocional e a síndrome de burnout no setor de transporte coletivo urbano de Natal. Dissertação de Mestrado não-publicada, Departamento de Psicologia, Universidade Federal do Rio Grande do Norte, Natal, RN.

Gil-Monte, P. R. (2002). Influencia del genero sobre el proceso de desarrollo del síndrome de quemarse por el trabajo (burnout) em profesionales de enfermería. Psicologia em Estudo, 1, 3-10.

Gil-Monte, P. R. (2005). El síndrome de quemarse por el trabajo (burnout): una enfermedad laboral en la sociedad del bienestar. Madrid, España: Pirâmide.

Gil-Monte, P. R., Carretero, N., \& Roldán, M. (2005). Algunos procesos psicosociales sobre el síndrome de quemarse por el trabajo (burnout) en profesionales de enfermería. Ansiedad y Estrés, 2/3(11), 281-290.

Gil-Monte, P. R., \& Peiró, J. M. (1997). Desgaste psíquico en el trabajo: el síndrome de quemarse. Madrid, España: Síntesis.

Janssen, P., Schaufeli, W, B., \& Houkes, I. (1999). Work-related and individual determinants of the three burnout dimensions. Work \& Stress, 13(1), 70-86.

Lautert, L. (1997). O desgaste profissional: Estudo empírico com enfermeiras que trabalham em hospitais. Revista Gaúcha de Enfermagem, 18(2), 133-144.

Lee, R. T., \& Ashforth, B. E. (1996). A meta-analytic examination of the correlates of the three dimensions of job burnout. Journal of Applied Psychology, 81(2), 123-133.

Lopes, M. J. M. (1996). O sexo do hospital. In M. J. M., Lopes, D. E., Meyer, \& V. R. Waldow (Eds.), Gênero e saúde (pp. 76-105). Porto Alegre, RS: Artes Médicas.

Maslach, C. (2000). A multidimensional theory of burnout. In C. L. Cooper (Ed.), Theories of organizational stress ( $\mathrm{pp}$. 68-85). Norfolk, UK: Oxford University Press.

Maslach, C. (2005). Entendendo o burnout. In A. M. Rossi, P. L., Perrewé, \& S. L. Sauter (Eds.), Stress e qualidade de vida no trabalho (pp. 41-55). São Paulo, SP: Atlas.

Maslach, C., \& Jackson, S. (1986). Maslach Burnout Inventory. Palo Alto, CA: Consulting Psychologist Press.

Maslach, C., \& Leiter, M. P. (1997). The truth about burnout: How organizations cause personal stress and what to do about it. San Francisco: Jossey Bass.

Maslach, C., Schaufeli, W. B., \& Leiter, M. P. (2001). Job burnout. Annual Review of Psychology, 52, 397-422.

Murofuse, N. T., Abranches, S. S., \& Napoleão, A. A. (2005). Reflexões sobre estresse e burnout e a relação com a enfer- magem. Revista Latino-Americana de Enfermagem, 13(2), 255-261.

Patrick, K., \& Lavery, J. E. (2007). Burnout in nursing. Australian Journal of Advanced Nursing, 24(3), 43-48.

Payne, N. (2001). Occupational stressors and coping as determinants of burnout in female hospice nurses. Journal of Advanced Nursing, 33(3), 396-405.

Pronost, A. M., \& Tap, P. (1996). La prévention du burnout et sés incidences sur lês stratégies de coping. Psychologie Francaise, 41(2), 165-172.

Schaufeli, W. B., \& Enzmann, D. (1998). The burnout companion to study and practice. London: Taylor \& Francis.

Shimizu, H., \& Ciampone, M. H. (2004). As representações dos técnicos e auxiliares de enfermagem acerca do trabalho em equipe na unidade de terapia intensiva. Revista Latinoamericana de Enfermagem, 12(4), 623-630.

Tabachinick, B. G., \& Fidell, L. S. (1996). Using multivariate statistics. New York: Harper Collins.

Tamayo, M. R. (1997). Relação entre a síndrome de burnout e os valores organizacionais no pessoal de enfermagem de dois hospitais públicos. Dissertação de Mestrado não-publicada, Instituto de Psicologia, Universidade de Brasília, DF.

Tamayo, M. R. (2008). Burnout: Aspectos gerais e relação com o estresse no trabalho. In A. Tamayo (Ed.), Estresse e cultura organizacional (pp. 75-105). São Paulo, SP: Casa do Psicólogo.

Tamayo, M. R., Argolo, J. C. T., \& Borges, L. O. (2005). Burnout em profissionais de saúde: Um estudo com trabalhadores do município de Natal. In L. O. Borges (Ed.), Os profissionais de saúde e o seu trabalho (pp. 223-246). São Paulo, SP: Casa do Psicólogo.

Tamayo, M. R., \& Silva, C. M. (2006). Burnout: Implicações da percepção de suporte organizacional no setor policial. In International Stress Management Association no Brasil (Ed.), VI Congresso de Stress da ISMA-BR e VIII Fórum Internacional de Qualidade de Vida no Trabalho [CD-ROM]. Porto Alegre, RS: International Stress Management Association no Brasil.

Tamayo, M. R., \& Tróccoli, B. T. (2002a). Exaustão emocional: Relações com a percepção de suporte organizacional e com as estratégias de coping no trabalho. Estudos de Psicologia (Natal), 7(1), 37-42.

Tamayo, M. R., \& Tróccoli, B. T. (2002b). Burnout no trabalho. In A. M. Mendes, L. O. Borges, \& M. C. Ferreira (Eds.), Trabalho em transição, saúde em risco (pp. 43-63). Brasília, DF: Editora da Universidade de Brasília.

Tamayo, M. R., \& Tróccoli, B. T. (2005). Validação da Escala de Caracterização do Burnout (ECB) [Resumo]. In União Latino-Americana de Entidades de Psicologia (Ed.), I Congresso Latino-Americano da Psicologia. Resumos [CDROM]. São Paulo, SP: ULAPSI.

Wilkinson, S. M. (1994). Stress in cancer nursing: Does it really exist? Journal of Advanced Nursing, 20, 1079-1084. 